STUDI

FRANCESI

\section{Studi Francesi}

Rivista quadrimestrale fondata da Franco Simone

185 (LXII | II) | 2018

OCTAVE MIRBEAU: UNE CONSCIENCE AU TOURNANT

DU SIEECLE - sous la direction de Ida Merello

\title{
MICHEL GUÉRIN, Le cimetière marin au boléro. Un commentaire du poème de Paul Valéry
}

Sara Amadori

\section{(2) OpenEdition \\ Journals}

Edizione digitale

URL: https://journals.openedition.org/studifrancesi/14033

DOI: $10.4000 /$ studifrancesi. 14033

ISSN: 2421-5856

Editore

Rosenberg \& Sellier

\section{Edizione cartacea}

Data di pubblicazione: 1 août 2018

Paginazione: 357-358

ISSN: 0039-2944

\section{Notizia bibliografica digitale}

Sara Amadori, «MICHEL GUÉRIN, Le cimetière marin au boléro. Un commentaire du poème de Paul Valéry»,

Studi Francesi [Online], 185 (LXII | II) | 2018, online dal 01 août 2018, consultato il 15 novembre 2021

URL: http://journals.openedition.org/studifrancesi/14033 ; DOI: https://doi.org/10.4000/studifrancesi. 14033

Questo documento è stato generato automaticamente il 15 novembre 2021.

\section{(c) (1)}

Studi Francesi è distribuita con Licenza Creative Commons Attribuzione - Non commerciale - Non opere derivate 4.0 Internazionale. 


\title{
MICHEL GUÉRIN, Le cimetière marin au boléro. Un commentaire du poème de Paul Valéry
}

\author{
Sara Amadori
}

\section{NOTIZIA}

MICHEL GUÉRIN, Le cimetière marin au boléro. Un commentaire du poème de Paul Valéry, Paris, Les Belles Lettres, 2017, «Encre marine», 158 pp.

1 Guérin, scrittore, filosofo e professore emerito dell'Université d'Aix-Marseille, propone in questo volume la sua lettura di uno dei testi più celebri di Paul Valéry: Le cimetière marin. Preceduto dalla versione integrale della poesia, il suo commento filosofico ne è al contempo un'esegesi e un'interpretazione musicale, che si iscrive, rinnovandola, nella tradizione inaugurata dai commenti di Gustave Cohen, professore alla Sorbonne, e del filosofo Alain. Il libro si apre con un «Prélude» (pp.17-39), nel quale Guérin accetta a sua volta la sfida di rispondere col proprio canto filosofico al richiamo di quello del poeta.

2 La tesi di Guérin è che esiste un legame, di natura estetica, tra Le cimetière marin e il Boléro di Ravel. Il caratteristico crescendo del Boléro può essere paragonato, a suo avviso, a quella peculiare tensione melodica che percorre tutto Le cimetière marin e sfocia nel torrente ritmico, nell'esplosione musicale che chiude il componimento: «Voilà ce qui rapproche le Boléro et le poème le plus célèbre de Paul Valéry: le sentiment, qui n'en reste pas à la représentation mais s'insinue par le corps, d'une entité libre, d'un engin dynamique chargé de communiquer à tout ce qui passe à proximité une vibration incomparable» (p. 38).

3 Tutto il commento è dunque finalizzato a presentare il testo di Valéry come una vera $\mathrm{e}$ propria danza verbale in tre movimenti, scanditi in otto strofe di decasillabi. La sezione «Commentaire» (pp. 41-146) si focalizza sulla progressione tematica e sull'evoluzione 
melodica del testo, soffermandosi su ogni singola strofa e facendo emergere «la manière dont procède en toute conscience le poète pour créer une émulation entre le sens et le son, entre la pensée verbale et la scansion rythmique» (p. 82). Tale sezione si suddivide a sua volta in tre sottosezioni: «Soleil! Soleil!...Faute éclatante!» (strofe 1-8), «La blanche espèce» (strofe 9-16), «Il faut tenter de vivre» (strofe 17-24). La prima sottosezione evidenzia come il testo di Valéry sia alimentato da un pensiero poeticofilosofico che, senza voler essere una riflessione astratta sull'Essere, diventa linfa vitale della creazione estetica. I suoi filosofemi sono, secondo Guérin, condensati di pensiero e immagini, la cui portata sensibile, e talora sensuale, è parte integrante del progetto di Valéry di produrre un legame osmotico, poroso, tra poesia ed esistenza.

Il timbro filosofico del testo tende a stemperarsi nella successiva sottosezione, in cui la parola poetica si apre alla dimensione dell'esistenza, e al suo fine ultimo: la morte. «La blanche espèce» è, infatti, quella che popola il cimitero e che conferma l'evidenza luminosa che la condizione umana è necessariamente priva d'Essere. Al vano e illusorio desiderio di eternità si sostituisce così una calda, confortante, consapevolezza dell'autenticità del nostro essere mortali, e della necessità di accettare questa condizione. Proprio in nome di tale consapevolezza «Il faut tenter de vivre», come suggerisce il titolo della terza sottosezione, che offre l'esempio ammirabile del verme, questo "parasite permanent de mon vœu de paresse plénière [...] [qui] vit de vie» (p. 125), secondo il filosofo. La progressione di Le cimetière marin determina così una graduale presa di coscienza, sintetizzata dall'immagine del mare, simbolo per Guérin dell'animo umano, per via della sua eterna, immutabile, motilità.

5 Tutto il commento si accorda, per il tenore riflessivo come per la qualità letteraria della scrittura, alla tensione poetica e melodica del testo di Valéry. Solo una parola che a sua volta sa farsi poesia e musica può rispondere degnamente al canto del poeta: rivolgendosi all'intelletto e toccando al contempo le corde più sensibili dell'emozione, saprà così essere in sintonia con la più intima essenza di Le cimetière marin, con il suo potere unico di «croiser une pensée de l'affectivité avec l'affectivité de la pensée» (p. 152), come Guérin constata nella sezione «Finale» (pp. 147-155). 